\title{
Technical assessment of LED and induction street lighting for a power utility in Malaysia
}

\author{
N. D. R. Mohd Zin \& K. Abdullah \\ Energy System, Distribution Department, TNB Research, Malaysia
}

\begin{abstract}
Various 'green' technologies in street lighting such as the light emitting diode (LED) and induction lighting have recently emerged as energy efficient, low maintenance alternatives to High Pressure Sodium Vapor (HPSV) street lighting. The Malaysian power utility, TNB, has recently carried a feasibility study to assess and evaluate the deployment of LED street light technology and induction street lighting as an alternative to the present conventional technologies of HPSV. In this study, the performance of several LED and induction street light technologies, in terms of energy saving, photometric performance, are evaluated and assessed. The study involves the installation of LED and induction street lights on site and the measurement of their photometric performance at the site. The LED and induction street lights are sourced from various manufacturers with different technologies. The study indicated that LED street lighting can provide between a 40 to $60 \%$ energy saving to the utility whereas induction street lights can provide a $20 \%$ energy saving. Most of the LED and induction street lights surveyed are also provided with a better Ingress Protection (IP) rating and color rendering index (CRI) compared to HPSV street lights.
\end{abstract}

Keywords: light emitting diode (LED), induction, street light, energy saving.

\section{Introduction}

Street lights are a major requirement in today's life of transportation for safety purposes and avoiding accidents during night. For several decades, the high pressure sodium lamp has been considered a standard for street lighting around the world. However, recently there have been major technological advances for street lighting purposes. New technology light sources include of light emitting diode (LED) and induction. Each of the new technologies that are presently available 
has advantages such as energy efficiency, light quality, durability and cost. Most of the LED street lights and induction street lights surveyed are provided with better Ingress Protection (IP) rating and color rendering index (CRI) compared to HPSV street light [1-4]. Many countries has taken the opportunity to implement LED street light and the result of other study [5] showed a higher energy saving and reduce in maintenance cost.

A feasibility study of LED and induction street lighting implementation for Malaysia power utility, Tenaga Nasional (TNB) is carried out by TNB Research, research arm of TNB. The study describes an assessment of LED street lighting technology and induction street lighting technology as an alternative to the present conventional High Pressure Sodium Vapor (HPSV) street light by performing an evaluation of the suitability of implementing LED street lights and induction street lights for TNB street lighting system. Four different technologies and makes of LED street lights and induction street lights are involved in this study, where their performance in terms of reliability, photometric quality, energy saving and electrical characteristic are evaluated and assessed by means of field measurement.

\section{Methodology and findings}

\subsection{LED street lights and induction street lights selection and field trial}

Four pilot LED and induction street light technologies from different countries and manufacturers were selected for this study and installed in Malaysia. The rated power consumption of the LED and induction street lighting technologies ranges from 90 Watts to 120 Watts. The sites were chosen based on few criteria such as sufficient length of straight roadways with easy access for photometric measurement purpose. The sites shall also have minimum environmental interference such as trees and lighting from other sources which may affect the accuracy of photometric measurement results.

A total of 80 LED and induction luminaires were installed at selected public roadways in two different state since March 2012. In all types of luminaires, average and uniformity of illuminance and luminance were measured in order to guarantee level requirements recommended by MS825 Part 1 (Code of Practice for the Design of Road Lighting - Part 1: Lighting of Roads and Public Amenity Areas (Rev 1)) [6].
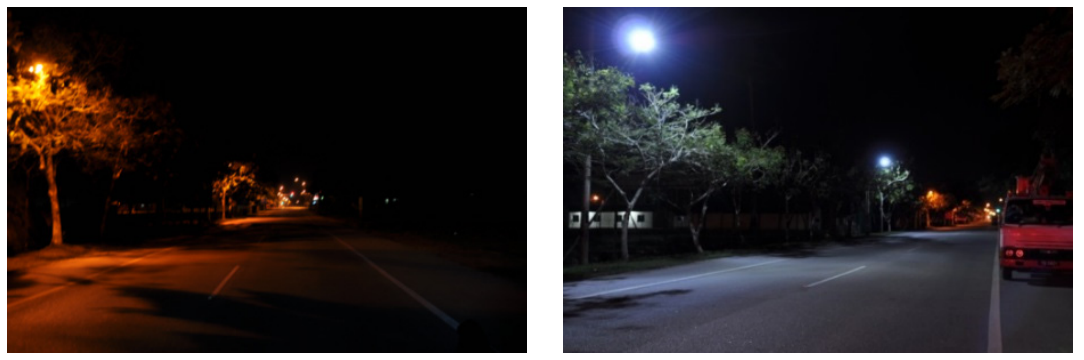

Figure 1: LED street lights before and after installation. 

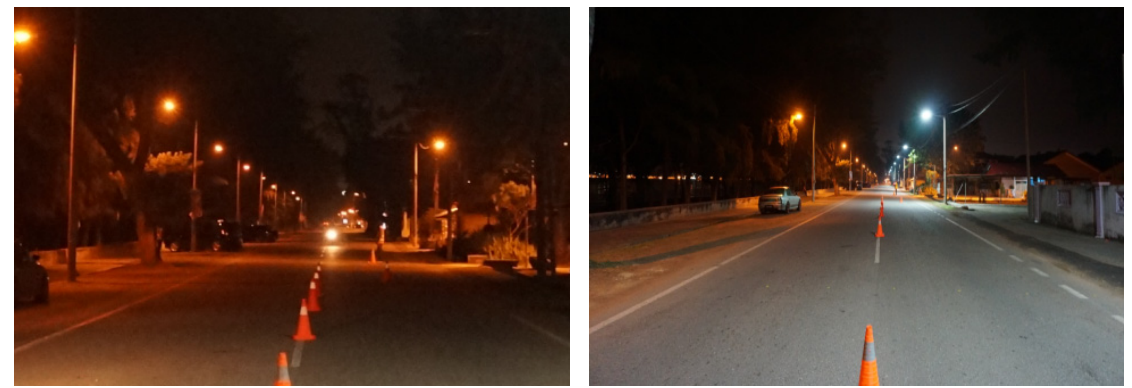

Figure 2: Induction street lights before and after installation.

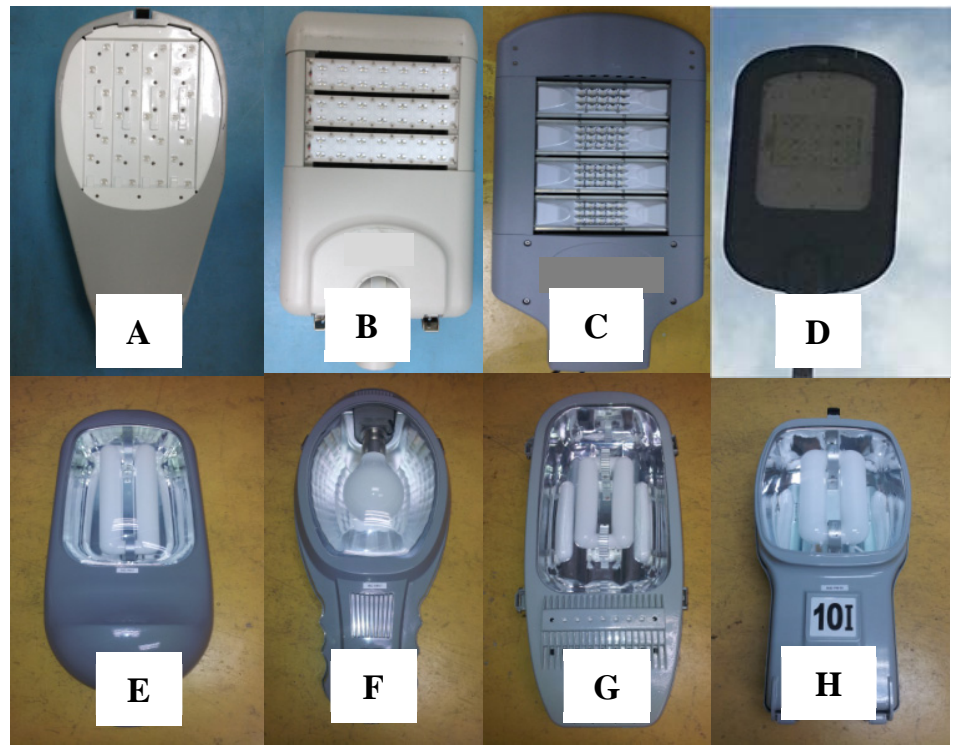

Figure 3: LED street lighting and induction street lighting technologies.

\subsection{LED luminaires and induction luminaires performance assessment}

It is known that LED luminaires and induction luminaires consume less energy compared to HPSV luminaires. However, other important parameters such as photometric performance and electrical characteristics have to be considered prior to the installation of LED luminaires. Power, energy and electrical characteristics measurement are carried out to confirm that the luminaires are operating within the manufacturer specifications and comply with certain standards.

In this study, the photometric performance assessment of LED street lighting and induction street lighting as an alternative source to the present conventional High Pressure Sodium Vapor (HPSV) street lighting were assessed. Street lighting standards are based on quantitative measurements of various parameters such as luminance, illuminance and lateral light distribution. At this moment, these are the 
important criteria for road user in order to achieve high quality street lighting. Field photometric measurements are required to determine their compliances with MS825 Part 1. MS825 Part 1 includes the parameters such as uniformity, minimum illuminance, average luminance and illuminance [6]. Uniformity refers to the evenness of the distribution of light on a surface. It is important due for human eyes to adjust to various light levels especially when driving.

\subsubsection{Photometric performance}

Photometric measurements based on CIE140 - 2000 (Road Lighting Calculation) were performed for each LED technology and induction technology during the one year field trial period [7]. The measurement was set up on $35 \mathrm{~m}$ pole to pole distance, $8 \mathrm{~m}$ pole height and $1.5 \mathrm{~m}$ distance from pole to roadway. For comparison purposes, the measured values are compared with the simulated photometric provided by the manufacturers. In addition, the results were used to monitor the lumen output over time to determine the life expectancy.

Measured illuminance and luminance levels for each LED street light and induction street light technology are shown in Tables 1 and 2. Not all of the installed products performed equally, photometric measurements highlighted in green indicate that the photometric measurement results complied with the minimum requirement for TNB road class as in MS825 Part 1, whereas the blue ones do not comply. The results show that all 4 LED street light technologies comply with the standard whereas induction street light technologies two induction street light technologies comply with the standard of ME4 and one induction street light technologies comply with the standard of P3, whereas others do not comply.

Table 1: Measured illuminance and luminance levels of the LED street light technologies.

\begin{tabular}{|c|c|c|c|c|}
\hline $\begin{array}{l}\text { LED street } \\
\text { light } \\
\text { Technologies }\end{array}$ & $\begin{array}{l}\text { Luminance, } \\
\text { Uo }\left(\mathrm{Cd} / \mathbf{m}^{2}\right)\end{array}$ & $\begin{array}{c}\text { Luminance } \\
\text { Ave. }\left(\mathrm{Cd} / \mathrm{m}^{2}\right)\end{array}$ & $\begin{array}{l}\text { Illuminance } \\
\text { Ave. (Lux) }\end{array}$ & $\begin{array}{l}\text { Illuminance } \\
\text { Min. (Lux) }\end{array}$ \\
\hline $\mathrm{A}$ & 0.59 & 1.17 & 10.83 & 6.20 \\
\hline B & 0.54 & 1.57 & 14.92 & 8.60 \\
\hline $\mathrm{C}$ & 0.45 & 1.02 & 18.24 & 6.45 \\
\hline $\mathrm{D}$ & 0.41 & 0.98 & 11.28 & 2.43 \\
\hline
\end{tabular}

Table 2: $\quad$ Measured illuminance and luminance levels of the induction street light technologies.

\begin{tabular}{|c|c|c|c|c|}
\hline $\begin{array}{c}\begin{array}{c}\text { Induction street } \\
\text { light } \\
\text { Technologies }\end{array} \\
\end{array}$ & $\begin{array}{l}\text { Luminance, } \\
\text { Uo }\left(\mathrm{Cd} / \mathbf{m}^{2}\right)\end{array}$ & $\begin{array}{l}\text { Luminance } \\
\text { Ave. }\left(\mathrm{Cd} / \mathrm{m}^{2}\right)\end{array}$ & $\begin{array}{l}\text { Illuminance } \\
\text { Ave. (Lux) }\end{array}$ & $\begin{array}{l}\text { Illuminance } \\
\text { Min. (Lux) }\end{array}$ \\
\hline $\mathrm{E}$ & 0.40 & 1.33 & 13.27 & 1.14 \\
\hline F & 0.28 & 0.87 & 13.14 & 0.85 \\
\hline $\mathrm{G}$ & 0.51 & 0.82 & 11.00 & 1.39 \\
\hline $\mathrm{H}$ & 0.30 & 0.66 & 10.49 & 1.76 \\
\hline
\end{tabular}


The measured colour rendering index (CRI) and colour correlated temperature (CCT) for each LED street light and induction street light technology are shown in Tables 3 and 4. The CRI and CCT of LED street light and induction street light technology both higher than HPSV street light which will deliver accurate colour rendering for maximum visibility and uniformity.

Table 3: Measured CRI and CCT of the LED street light technologies.

\begin{tabular}{|c|c|c|}
\hline $\begin{array}{c}\text { LED street light } \\
\text { Technologies }\end{array}$ & CRI (Ra) & CCT (K) \\
\hline A & 67 & 3960 \\
\hline B & 80 & 4981 \\
\hline C & 73 & 7803 \\
\hline D & 70 & 5603 \\
\hline
\end{tabular}

Table 4: Measured CRI and CCT of the induction street light technologies.

\begin{tabular}{|c|c|c|}
\hline $\begin{array}{c}\text { Induction street } \\
\text { light Technologies }\end{array}$ & CRI (Ra) & CCT (K) \\
\hline E & 75 & 4771 \\
\hline F & 73 & 4907 \\
\hline G & 75 & 4964 \\
\hline H & 75 & 4788 \\
\hline
\end{tabular}

From the same equipment, Konica Minolta CL500A, the spectral distribution of each of the LED street light technology and induction street light technology is shown in Figure 4. The spectral distribution of the optical source determines the performance of the optical system through the dispersion. Based from the figure 4, the LED street light technology used the phosphor conversion (PC) LED which combines a blue component with a broad phosphor emission. The induction street light technology is emitted by trichromatic coating in lamp which is similar with full spectrum emitted by red, green and blue lamp.

\section{Conclusion}

Technically, LED luminaires have the potential to be adopted as they exceed HPSV in terms of energy saving, electrical characteristics, colour temperature and CRI. Based on the photometric measurement in this study, all of the LED street lights technologies complied with the TNB road class lighting requirement as in the MS825 whereas induction street light technologies did not comply. The relationship between the luminance at the observer's eye level and the illuminance depend on the luminance distribution of the LED street light and induction street light technology. This shows that an LED street light technology has excessive advantages compare to induction street light and HPSV street light. It is also feasible for TNB to have one to one replacement of the existing 150 Watts HPSV luminaires with the LED luminaires. 

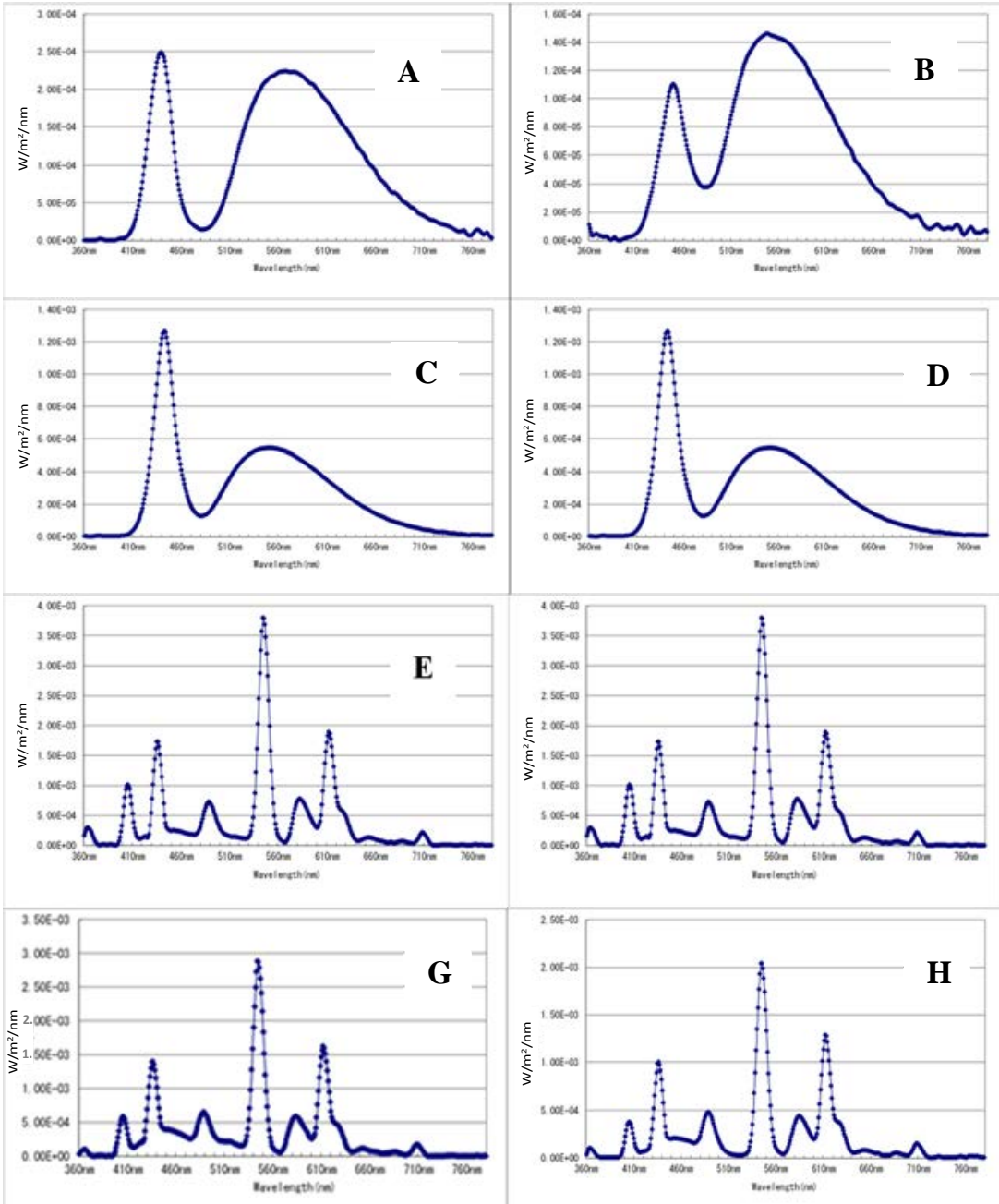

Figure 4: Spectral Distribution for LED street light and induction street light technology.

With the rapid and continuous improvement of LED street light design and technology, it is expected that they can offer better energy saving, lower maintenance cost and better environmental impact. However, few disadvantages of LED street lights such as high initial unit cost and unproven long term reliability performance need to be addressed and further studied by TNB before any concrete decision on the implementation of LED street lighting system can be made. In addition, standards related to LED street light and its components are currently being developed by respective international bodies and committees as many parties and organizations throughout the world are still piloting the LED luminaires. 


\section{References}

[1] S. Department of Energy, “Color Quality of White LEDs”, Jan 2008.

[2] T. Cook, J. Shackelford, M. Johnson, T. Pang, "Light and Color Methods of Achieving High CRI with LEDs”, 2011 http://ledlight.osram-os.com/wpcontent/uploads/2012/02/OSRAM-OS_WEBINAR_HighCRI_06-26-12.pdf

[3] US Department of Energy, LED Color Characteristics, Jan 2012.

[4] Wikipedia, "Fluorescent lighting spectrum peaks labelled", Wikipedia, 18 May 2011,

http://en.wikipedia.org/wiki/File:Fluorescent_lighting_spectrum_peaks_labe lled.svg

[5] US Department of Energy, "Demonstration Assessment of Light Emitting Diode (LED) Street Lighting, Phase III Continuation”, November 2008.

[6] Malaysian Standard, MS825 Part 1 (Code of Practice for the Design of Road Lighting - Part 1: Lighting of Roads and Public Amenity Areas), 2007.

[7] International Commission on Illumination, CIE140 - Road Lighting Calculations, 2000. 